\title{
Malignant Carcinoid Tumor of the Rectum in a Patient With Psoriatic Arthritis Treated With Etanercept
}

\author{
Diego Adrianzen Herrera ${ }^{\mathrm{a}, \mathrm{c}}$, Mahjabeen $\mathrm{Haq}^{\mathrm{a}}$, Nazia Hussain ${ }^{\mathrm{b}}$
}

\begin{abstract}
The connection between malignancy risk and tumor necrosis factor alpha (TNFa) inhibitors is still a working field. Generally, less attention has been paid to their association with solid tumors compared to the mostly accepted risk for lymphoma. Etanercept is somewhat underrepresented compared to other drugs in the class and entities other than rheumatoid arthritis (RA) have not been widely included in large cohort studies exploring malignancy correlations. Nonetheless, lymphoma association to etanercept has been found in some series and many solid malignancies cases in the context of etanercept use for conditions other than RA have been described as single reports. We present the first described case of rectal carcinoid tumor developing after treatment with etanercept in a patient with psoriatic arthritis and explore the literature for evidence about the association between solid tumors and etanercept use in autoimmune diseases.
\end{abstract}

Keywords: Etanercept; Carcinoid; Psoriatic arthritis

\section{Introduction}

Tumor necrosis factor alpha (TNFa) inhibitors have become an important treatment option for several inflammatory conditions and are considered a milestone in the therapy of rheumatic diseases. However, blocking this inflammatory cytokine, involved in the development of synovitis and joint destruction, also interferes with its role in lysing tumors and regulating the apoptotic cell cycle, there-

Manuscript accepted for publication July 16, 2015

anternal Medicine Residency Program, Mount Sinai St. Luke's and Roosevelt Hospitals, Icahn School of Medicine at Mount Sinai, Mount Sinai Health System, New York, NY, USA

bMedicine Department, Rheumatology Division, Mount Sinai St. Luke's and Roosevelt Hospitals, Icahn School of Medicine at Mount Sinai, Mount Sinai Health System, New York, NY, USA

${ }^{\mathrm{c} C}$ Corresponding Author: Diego Adrianzen Herrera, Internal Medicine Residency Program, Mount Sinai St. Luke's and Roosevelt Hospitals, Icahn School of Medicine at Mount Sinai, Mount Sinai Health System, 515 West 59th Street, Apt 10J, New York, NY 10019, USA. Email: dadrianzenherrera@chpnet.org

doi: http://dx.doi.org/10.14740/jmc2248w fore causing a theoretical risk for malignancy. Most empirical evidence on this regard comes from post-marketing experience and clinical practice [1]. Its study is a challenge since concomitantly used medications may also confer similar risks and there is an inherent malignancy association in several autoimmune diseases [2].

It is widely accepted that TNFa inhibitors confer an increased risk for malignancy, especially for lymphoma, based on several trials and meta-analyses [3]. This relationship has mainly been studied in rheumatoid arthritis (RA), initially from reports to the US Food and Drug Administration (FDA) [4] and later by series of increased rates of lymphomas after starting all types of TNFa inhibitors for RA [5] as well as specific etanercept series [6]. There are, however, smaller series in RA that found no difference in lymphoma rates with or without TNFa inhibitor treatment [7], suggesting that RA itself, and not the treatment used, might account for the observed association.

Although initially extrapolated from the RA studies, lymphoma concerns have been specifically addressed in psoriatic arthritis (PsA) as well. While studies comparing malignancy incidences between PsA and RA from large cohorts in the United States suggest similar increased malignancy subtypes rates [8], a study in Sweden showed that, in contrast to RA, the risk of lymphoma in PsA was not higher than that of a control population, nor did TNFa inhibitors affect this risk [9].

More recent trials explored TNFa inhibitors' association with solid malignancies. A meta-analysis including over 5,000 patients and placebo-controlled trials of RA treated with infliximab or adalimumab concluded that malignancies, including solid tumors, were not only significantly more common with TNFa inhibitor treatment, but also showed a dose-dependent increased risk of malignancy for these agents [10]. Data in PsA, however, are conflicted, with some reviews showing no solid malignancy association with the use of TNFa inhibitors [11, 12].

TNFa inhibitors have been mostly studied as a group and etanercept has been underrepresented. When individually analyzed, two etanercept series have shown significant correlation with solid malignancies when used for Wegener's disease [13] and with non-melanoma skin cancers in psoriasis [14] while one study found no increase in overall malignancies in psoriasis [15].

\section{Case Report}

A 45-year-old Hispanic female with a history of psoriasis since 
childhood first developed bilateral symmetrical polyarticular arthralgias at age 33. On initial presentation, she had bilateral humeroradial, radiocarpal, metacarpophalangeal, proximal and distal interphalangeal joint pain associated for morning stiffness. Her symptoms worsen progressively over the course of a year and she was subsequently diagnosed with psoriatic arthropathy after serological studies for rheumatoid factor (RF), anti-cyclic citrullinated peptide antibodies (anti-CCP $\mathrm{Ab}$ ), anti-Smith antibody (anti-Sm), anti-Sjogren's syndromerelated antigen A (anti-SS-A), Sjogren syndrome antigen B (SS-B), U1 ribonucleoprotein antibodies (anti-RNP), and antinuclear antibodies (ANA) tested negative.

After treatment with varying doses of methotrexate for approximately 2 years with poor response, addition of a biological agent was considered and etanercept was started, with subsequent significant symptomatic improvement and maintenance of stable disease for long time. Several years into the treatment, an intractable upper respiratory tract infection mandated holding of the biologic agent which resulted in significant recrudescence of arthritis and psoriasis manifesting with pain and new scalp lesions. A re-challenge with etanercept showed excellent symptomatic control and maintenance treatment was permanently resumed.

Few months after restarting etanercept treatment, she developed intermittent but persistent diarrhea and her laboratory work showed new onset and mild anemia. These findings were attributed to side effects from methotrexate and the patient remained under careful monitoring; however, she subsequently developed occasional palpitations, hot flashes, profuse sweating episodes and worsening of baseline anemia. Workup for these new symptoms included colonoscopy study which found a rectal polyp for which pathology was consistent with a neuroendocrine tumor.

Aware of the theoretic malignancy potential of etanercept, the drug was promptly discontinued and the patient was referred for sigmoidoscopic surgical resection. Pathology showed a $1.1 \mathrm{~cm}$ low-grade well-differentiated rectal carcinoid tumor restricted to the lamina propia and submucosa, with minimal identified mitoses, a proliferation rate (Ki-67) of less than $1 \%$ and uninvolved circumferential margins. Immunohistochemical stains confirmed the histological diagnosis as tumor cells were positive for synaptophysin, chromogranin and CD56. After surgical resection the patient underwent medical oncology evaluation which included normal serum chromogranin A and urine 5-hydroxyindoleacetic acid (5-HIAA) levels as well as unremarkable contrasted computerized tomography scan of the chest, abdomen and pelvis and octreotide scintigraphy scan. After complete evaluation revealed no evidence of residual or metastatic disease, the tumor board consensus was yearly endoscopic surveillance according to National Comprehensive Cancer Network (NCCN) guidelines.

\section{Discussion}

There is no question that TNFa inhibitors play a key role in the modern treatment of PsA [1] but it is important to consider their potential side effects as biological medications [8]. As such, development of solid malignancies may be a particu- larly alarming potential side effect from TNFa inhibitors [10] but minimal data are available about this issue since studies have mostly concentrated on the relationship between $\mathrm{TNFa}$ inhibitor treated RA and lymphoma $[4,5]$; furthermore, most of them study other drugs in the group and etanercept is underrepresented $[3,5,10]$. Our case distinguishes from others as we report a solid tumor, not lymphoma, occurring in the setting of etanercept use for PsA, an entity much less explored than RA.

Despite a specific observational post-marketing study showed that rates of lymphomas, skin cancer and other malignancies were not higher than expected with the use of etanercept in psoriasis [14], it is worth pointing that it was a safety study and only explored cases requiring hospitalization and thus, could have certainly missed cases like ours.

We found several recently reported malignancy cases associated with etanercept in the literature. They include a patient who developed non-Hodgkin's lymphoma (NHL) after etanercept treatment for ankylosing spondylitis [16], a patient with rapid onset development of a rare human papilloma virus-negative squamous cell carcinoma of the penis shortly after starting etanercept therapy for psoriasis [17], a patient who developed oropharyngeal carcinoma after combination of methotrexate and etanercept for RA [18] and a series of seven patients who developed one or more squamous cell carcinoma after starting etanercept treatment for RA [19]. Also, although infrequent, solid tumor cases have been specifically reported in PsA patients treated with etanercept such as a primary thyroid marginal zone B-cell lymphoma [20] and a rare variant of squamous cell carcinoma called carcinoma cuniculatum [21].

Carcinoid tumors as the one we report have been described in other rheumatologic conditions treated with TNFa inhibitors such as an endobronchial carcinoid tumor found in a patient with Crohn's disease treated with adalimumab [22] and an atypical thymic carcinoid tumor was found in a patient treated with etanercept for unspecified refractory spondyloarthropathy [23]; however, they have also been reported in patients with autoimmune conditions not treated with TNFa inhibitors, specifically, a case of multicentric carcinoid tumor of the lung and rectum in a patient with PsA [24] and a pulmonary carcinoid tumor in a patient with RA [25].

To our knowledge, this is the first description of rectal carcinoid tumor in a patient treated with etanercept. This occurred in a patient with PsA and the time from treatment to tumor development was years. The only other carcinoid tumor described in a patient under treatment with etanercept is an atypical thymic carcinoid that developed 9 months after treatment initiation in a patient with unspecified spondyloarthropathy [23]. To the authors of that case, the rarity of the tumor location pointed to association between the two events; this of course is insufficient to prove causation, but it is interesting that the only other case of thymic malignancy in a patient receiving TNFa inhibitors occurred with etanercept [20].

Despite conflicting data, many clinicians would agree there is consensus about the risk of lymphoma $[4-6,10]$ but the potential of TNFa inhibitors to cause or facilitate the formation of solid malignant tumors still requires much study. As presented above, there have been several case reports of cutaneous solid malignancies developing after treatment with etanercept 
and in some of them the short time spam between initiation of the drug and the development of the tumor was used as indirect prove of association [17, 18]; other cases, however, do not follow this timeline pattern and long periods of time have been reported between initiation of etanercept and the development of the tumor, particularly in PsA [19]. Furthermore, the rapid onset may point to subclinical tumors already present at the time of initiating therapy that manifest clinically after the suppressed immunity conferred by the agent [19].

Since there are contradictory data and some studies even show no statistically significant increase in malignancy risk with TNFa inhibitors, it is impossible at this point to differentiate between causality and chance in our case. Nevertheless, although causality cannot not be proven from the collection of cases reported thus far, it is important to recognize that they inevitably generate the need to consider that TNFa inhibitors, like etanercept, by affecting the cytokine in all its functions, could potentially affect key regulatory steps in the apoptotic pathway in certain cell types leading to an increased risk of solid malignancies. Moreover, as it is the case for the response to the anti-inflammatory effect, the malignant potential could be determined by genetic factors and complex interactions between the biological drug and the host's cellular pathways [21]. We believe our patient represents another case pointing to the need for larger cohorts and basic science studies on patients receiving TNFa inhibitors and their potential increased risk for developing solid malignancies.

\section{Conflict of Interest}

The authors declare no conflict of interest.

\section{References}

1. Antoni C, Braun J. Side effects of anti-TNF therapy: current knowledge. Clin Exp Rheumatol. 2002;20(6 Suppl 28):S152-157.

2. Hemminki K, Liu X, Ji J, Sundquist J, Sundquist K. Autoimmune disease and subsequent digestive tract cancer by histology. Ann Oncol. 2012;23(4):927-933.

3. Ioannidis JP, Zhou Y, Chang CQ, Schully SD, Khoury MJ, Freedman AN. Potential increased risk of cancer from commonly used medications: an umbrella review of meta-analyses. Ann Oncol. 2014;25(1):16-23.

4. Brown SL, Greene MH, Gershon SK, Edwards ET, Braun MM. Tumor necrosis factor antagonist therapy and lymphoma development: twenty-six cases reported to the Food and Drug Administration. Arthritis Rheum. 2002;46(12):3151-3158.

5. Geborek P, Bladstrom A, Turesson C, Gulfe A, Petersson IF, Saxne T, Olsson H, et al. Tumour necrosis factor blockers do not increase overall tumour risk in patients with rheumatoid arthritis, but may be associated with an increased risk of lymphomas. Ann Rheum Dis. 2005;64(5):699-703.

6. FDA Arthritis Advisory Committee Meeting, 3/04. Available at: http://www.fda.gov/ohrms/dockets/ac/cder03.
html\#Arthritis (Accessed on April 30, 2015).

7. Aaltonen KJ, Joensuu JT, Virkki L, Sokka T, Aronen P, Relas H, Valleala H, et al. Rates of serious infections and malignancies among patients with rheumatoid arthritis receiving either tumor necrosis factor inhibitor or rituximab therapy. J Rheumatol. 2015;42(3):372-378.

8. Gross RL, Schwartzman-Morris JS, Krathen M, Reed G, Chang H, Saunders KC, Fisher MC, et al. A comparison of the malignancy incidence among patients with psoriatic arthritis and patients with rheumatoid arthritis in a large US cohort. Arthritis Rheumatol. 2014;66(6):1472-1481.

9. Hellgren K, Smedby KE, Backlin C, Sundstrom C, Feltelius N, Eriksson JK, Baecklund E, et al. Ankylosing spondylitis, psoriatic arthritis, and risk of malignant lymphoma: a cohort study based on nationwide prospectively recorded data from Sweden. Arthritis Rheumatol. 2014;66(5):1282-1290.

10. Bongartz T, Sutton AJ, Sweeting MJ, Buchan I, Matteson EL, Montori V. Anti-TNF antibody therapy in rheumatoid arthritis and the risk of serious infections and malignancies: systematic review and meta-analysis of rare harmful effects in randomized controlled trials. JAMA. 2006;295(19):2275-2285.

11. Armstrong AW, Coates LC, Espinoza LR, Ogdie AR, Rich P, Soriano ER. Infectious, oncologic, and autoimmune comorbidities of psoriasis and psoriatic arthritis: a report from the GRAPPA 2012 annual meeting. J Rheumatol. 2013;40(8):1438-1441.

12. Dommasch ED, Abuabara K, Shin DB, Nguyen J, Troxel $\mathrm{AB}$, Gelfand JM. The risk of infection and malignancy with tumor necrosis factor antagonists in adults with psoriatic disease: a systematic review and meta-analysis of randomized controlled trials. J Am Acad Dermatol. 2011;64(6):1035-1050.

13. Etanercept plus standard therapy for Wegener's granulomatosis. N Engl J Med. 2005;352(4):351-361.

14. Kimball AB, Rothman KJ, Kricorian G, Pariser D, Yamauchi PS, Menter A, Teller CF, et al. OBSERVE-5: observational postmarketing safety surveillance registry of etanercept for the treatment of psoriasis final 5-year results. J Am Acad Dermatol. 2015;72(1):115-122.

15. Pariser DM, Leonardi CL, Gordon K, Gottlieb AB, Tyring $\mathrm{S}$, Papp KA, Li J, et al. Integrated safety analysis: shortand long-term safety profiles of etanercept in patients with psoriasis. J Am Acad Dermatol. 2012;67(2):245256.

16. Aksu K, Cagirgan S, Ozsan N, Keser G, Sahin F. Non-Hodgkin's lymphoma following treatment with etanercept in ankylosing spondylitis. Rheumatol Int. 2011;31(12):1645-1647.

17. Fryrear RS, 2nd, Wiggins AK, Sangueza O, Yosipovitch G. Rapid onset of cutaneous squamous cell carcinoma of the penis in a patient with psoriasis on etanercept therapy. J Am Acad Dermatol. 2004;51(6):1026.

18. Chainani-Wu N, Chang C, Gross AJ, Yom SS, Silverman $\mathrm{S}$, Jr. Oropharyngeal carcinoma arising after methotrexate and etanercept therapy for rheumatoid arthritis. Oral Surg Oral Med Oral Pathol Oral Radiol. 2014;117(3):e261263. 
19. Smith KJ, Skelton HG. Rapid onset of cutaneous squamous cell carcinoma in patients with rheumatoid arthritis after starting tumor necrosis factor alpha receptor IgG1-Fc fusion complex therapy. J Am Acad Dermatol. 2001;45(6):953-956.

20. Jin H, Cho HH, Kim WJ, Mun JH, Song M, Kim HS, Ko $\mathrm{HC}$, et al. Primary thyroid marginal zone B-cell lymphoma in a patient with psoriatic arthritis treated with etanercept. J Am Acad Dermatol. 2014;71(4):e152-153.

21. Tchernev G, Guarneri C, Bevelacqua V, Wollina U. Carcinoma cuniculatum in course of etanercept: blocking autoimmunity but propagation of carcinogenesis? Int J Immunopathol Pharmacol. 2014;27(2):261-266.

22. Carcano C, Oliveira EC, Martinez F, Kirsch J. Endobron- chial carcinoid tumor in a Crohn disease patient treated with a TNFalpha inhibitor. Transl Lung Cancer Res. 2013;2(1):E29-32.

23. Simsek I, Pay S, Dinc A, Erdem H, Kurt B. Atypical carcinoid tumor of the thymus with ectopic ACTH production developed during the course of etanercept treatment-case report. Clin Rheumatol. 2007;26(9):1561-1562.

24. George N, Depala A, Al Sweedan L, Chakravarty K. A case of multicentric carcinoid in a patient with psoriatic spondyloarthropathy. Case Rep Rheumatol. 2015;2015:179696.

25. Sayarlioglu M, Izmirli M, Uzum K, Alici S, Erkoc R. Rheumatoid arthritis and pulmonary carcinoid tumor. Eur J Gen Med. 2005;2(1):35-38 